\title{
AiMT
}

Advances in Military Technology

Vol. 11, No. 2 (2016), pp. 197-209

ISSN 1802-2308, eISSN 2533-4123

DOI 10.3849/aimt.01106

\section{Acceptable Risk in Military Bridge Evaluation}

\author{
A.J. MacDonald ${ }^{1,3 *}$, R. Gordon Wight ${ }^{1}$ and F. Michael Bartlett ${ }^{1,2}$ \\ ${ }^{1}$ Royal Military College of Canada, Kingston, Ontario, Canada \\ ${ }^{2}$ Faculty of Engineering, Western University, London, Ontario, Canada \\ ${ }^{3}$ McCall Engineering Limited, Victoria, British Columbia, Canada
}

The manuscript was received on 7 February 2016 and was accepted after revision for publication on 29 November 2016.

\begin{abstract}
:
In military bridge evaluation, acceptable life-safety risk in crossings should be aligned with the acceptable life-safety risk of the associated military operation. A continuum of acceptable life-safety risk exists for military operations, thus a continuum of acceptable life-safety risk for military vehicles crossing bridges exists. The paper relates military mission life-safety acceptable risk levels to acceptable bridge crossing life-safety risk in an approximate quantitative manner. A continuum of acceptable life-safety risk for military bridge crossings provides flexibility in mission planning and execution, while providing engineers a basis to conduct military bridge evaluation that is consistent with the mission intent.
\end{abstract}

\section{Keywords:}

acceptable risk, bridge evaluation, life-safety, military risk, operations

\section{Acceptable Risk for Military Bridges}

Effective application of Limit State Design (similar to Load and Resistance Factor Design (LRFD)) principles requires the probabilistic quantification of loads and resistances and selection of suitable target reliability indices, typically on the basis of acceptable life-safety risk [1]. Target reliability indices for structural design are normally calibrated for the design of individual elements within a structural system. The reliability of the system, which is indicative as to the life-safety risk of using the structure, correlates to the reliability of its structural elements. Acceptable bridge crossing risk in the context of military operations has not been previously explored and thus needs to be defined. "Acceptable levels of risk attaining a limit state, to be used as targets in design, should be assessed with due regard to the social and economic criteria applicable to the structures under consideration" [2]. Without a defined

\footnotetext{
* Corresponding author: Military Engineering Research Group, Royal Military College of Canada, K7K 7B4 Kingston, Ontario, Canada.

Phone: 1-647-207-0449, E-mail: AndrewJames.Macdonald@rmc.ca
} 
acceptable risk and probabilistic quantification of military vehicle loads, Limit-Statesbased bridge design and evaluation methods will not be adopted for general military use.

The quantification of acceptable life-safety risk, defined herein as the annual probability of fatality, must reflect unique circumstances when evaluating bridges for military use. Given the unlimited liability expected of those in military service, the acceptable life-safety risk for military personnel may be higher than that for the civilian population they serve [3]. This paper therefore seeks to define the maximum acceptable life-safety risk based solely on such considerations of social acceptability, i.e., without considering economic, optimization, or other factors. This therefore represents an upper limit of life-safety risk for military bridge evaluation. As defined by Mauch [4], this paper investigates objective risk, where for example "[a]n activity that produces 20 events in a decade with an effect of one fatality per event is assigned the same risk value as a single serious event during a decade with 20 fatalities" [4]. However, subjectively there is an aversion, given the same objective risk, for a greater number of fatalities per event [4]. Further investigation is required to quantify this aspect in a military context, where an additional factor may be applied where appropriate in evaluation. This is likely a worthwhile area of future research given, risk aversion to multiple fatality events qualitatively increases the "perception of risk to oneself, jeopardizing of the activity as a whole (e.g., in the military)" [4]. Where an enhanced perception of risk can impact the effectiveness of military units through increased levels of individual and collective stress, unwillingness to follow orders, and loss of unit cohesion, all of which could have an impact on mission success.

Previous research by Sykora et. al. [5], investigates socially acceptable risk criteria in structural element target reliability levels for the evaluation of bridges during emergency and crisis situations. Sykora et. al. [5] consider the risk associated with uncommon accidents as acceptable for "members of the rescue corps" during these situations. This further illustrates that, much like military personnel, it may be socially acceptable for certain individuals to assume a greater life-safety risk in the use of a structure under certain circumstances. Unlike Sykora et. al. [5], to avoid the system specific complexities associated with relating different levels of system reliability with associated structural element reliabilities, this paper only investigates the acceptable levels of risk of a structural system for a spectrum of military operations.

\section{Acceptable Risk and Military Operations}

Military operations inherently expose armed forces personnel to heightened risk levels due to [6]:

- the need for rapid execution of tasks;

- exposure to heavy specialized equipment;

- need to handle hazardous equipment and material (including lethal weapon systems whose intent is to maim or kill);

- exposure to actions of enemy forces;

- exposure to actions of friendly forces, such as friendly fire.

It is deemed acceptable that military personnel assume these heightened risk levels in light of the function they perform for the society they serve [3]. The purpose of a military fighting force is to impose the will and desire of the nation-state through the threat of force or the application of force up to and including the use of deadly force to 
achieve a political purpose. "By its very nature, the application of force will place individuals and resources in harm's way” [7].

\subsection{Mission Planning Factors and Life-safety Risk}

When conducting mission analysis, military planners must balance the cost of potential death or injury of personnel to the benefits of achieving the mission objective. At times, this requires some individuals to assume disproportionally higher risks than others. In military operations, exposing a few individuals to very high risk levels can ensure reduced risk to all other personnel involved in the operation. Given the complexities of both risk and military operations, risk management tools are implemented "to provide a decision process that will aid planners in identifying, analyzing, evaluating and controlling all types of risk" [7]. "A clear process of risk management is required in military planning to ensure that threats are fully considered, appropriate measures are taken to minimize their effects and that risk decisions are fully understood" [7]. In general, this process involves [8]:

- identifying hazards;

- determining impact these hazards have on mission accomplishment in terms of probability and consequence

- developing controls to mitigate the risk associated with hazards;

- developing, analyzing, and comparing courses of actions;

- deciding on a course of action;

- implementing of risk mitigation controls during task execution;

- supervising and re-evaluating during mission execution (which include adjusting to changes in the known situation);

- evaluating the mission to summarize lessons learned for next risk analysis cycle.

A main tenet of this process is to ensure that unnecessary risks are avoided, and that additional risk is only accepted "if the benefits outweigh the potential costs or losses” [8]. In the risk management process, even after risk mitigating measures are in place, residual risk will always exist; it is left to the commander to "decide whether to accept the level of residual risk to accomplish the mission" [8]. If the residual risk is greater than what has been deemed acceptable by higher command guidance, then subordinate commanders must "seek the higher commander's approval to accept risks" [8] or change the mission scope to reduce the residual risk to an acceptable level.

\subsection{Mission Risk Assessment}

Risk Management for CF Operations [7], provides a risk assessment matrix used in the risk management process where risks are defined in the context of accomplishing the mission. Similar to Canadian civilian standards [1], military mission risk is defined as the product of consequences and the associated probability of occurrence. Although expected personnel loss (which is essentially life-safety risk during the execution of the mission) is closely associated with the risk of not accomplishing the mission, defining mission risk does not categorically identify the acceptable life-safety risk to personnel [9]. Although the aim is to minimize losses while achieving the mission objective, it might be warranted to increase the risk of mission failure to lower the lifesafety risk to personnel or, conversely, to increase life-safety risk to minimize risk of mission failure. This decision is based on other considerations such as "the public reaction to [personnel] loss against national, strategic, operational or tactical objec- 
tives" [7] and the consequences of mission failure. Where at its extreme when "a leader's survival or when a regime, political, religious, ideological, or economic system is at stake, virtually any level of risk may be acceptable” [9].

\subsection{Acceptable Life-safety Risk}

When evaluating mission risk, the commander must consider the costs and benefits of having personnel assume additional risk to achieve the mission. Quantification of the appropriate life-safety risk while maintaining an acceptable likelihood of achieving the mission is a complicated procedure that uses incomplete situational information. It relies on personal experience and other human qualities, such as morale and esprit de corps, which are difficult to quantify methodically. Regardless of how a commander determines the appropriate life-safety risk for various sub-elements under his or her command, this information must be conveyed in a manner that is both reliable and easily understood. Wight [9] describes life-safety based on Acceptable Risk Levels (ARLs), shown in Tab. 1, that "would be a commander's directive to subordinates to shape further planning and execution decisions that specifies what level of potential losses is acceptable in order to achieve the mission objectives" [9]. These ARLs, are appropriate for use for engineering systems since they can be quantified in terms of probability of fatality per year. Where the probability of fatality per year, $P_{f y r}$, was not explicitly stated by Wight [9], these have been computed for each battle or conflict shown using

$$
P_{f y r}=1-\left(1-\frac{n_{\mathrm{d}}}{d_{\mathrm{p}}}\right)^{\frac{1 \text { year }}{T}},
$$

where:

- $n_{\mathrm{d}}$ denotes the number of military fatalities in the conflict;

- $n_{\mathrm{p}}$ is the total number of military personnel involved in the conflict;

- $T$ is the duration of the conflict in years.

Equation (1) is derived assuming that probability of fatality and total number of personnel remains constant over the duration of the conflict. In fact, the actual probability of fatality varies throughout the conflict.

\section{Acceptable Risk for Military Personnel during Bridge Crossing}

Tab. 1 indicates clearly that, in military operations, a continuum of acceptable risk exists that depends on the conflict, operation, mission and individual. It would clearly be unreasonable to assign a single value to the acceptable risk for participation by military personnel in ancillary activities during military operations. There should therefore be a continuum of acceptable risk for military traffic crossing bridges that is aligned with the Acceptable Risk Level (ARL) of the military operation. Although other factors must be accounted for to quantify the optimum level of risk [1], this acceptable risk represents the upper bound risk level that should be accepted for bridge crossings. Military planners should also consider if civilian traffic (vehicular or pedestrian) will be present when military vehicles are traversing the bridge. In this case, the civilians would be exposed to the same risk as the military personnel, so the acceptable risk may be lowered from that corresponding to the ARL to that considered acceptable for civilians. This socially acceptable risk for civilians will depend on the situation. 
Tab. 1 Acceptable Risk Level (ARL) and associated annual probability of fatality for conflict or battle within ARL

\begin{tabular}{|c|c|c|c|c|}
\hline ARL & $\begin{array}{l}\text { Order of magni- } \\
\text { tude of probability } \\
\text { of fatality per } \\
\text { year }(\%)\end{array}$ & $\begin{array}{c}\text { Example } \\
\text { within ARL }\end{array}$ & $\begin{array}{r}\text { Probability of } \mathbf{f} \\
\text { year (\%) for a } \\
\text { involved unles } \\
\text { otherw }\end{array}$ & $\begin{array}{l}\text { ality per } \\
\text { persons } \\
\text { pecified } \\
\text { e }\end{array}$ \\
\hline \multirow[b]{2}{*}{ Negligible } & \multirow[b]{2}{*}{0.01} & \multirow{2}{*}{$\begin{array}{l}\text { This is general } \\
\text { population rate } \\
\text { of death for } \\
20-24 \text { year olds }\end{array}$} & All Causes & $0.06^{\mathrm{a})}$ \\
\hline & & & $\begin{array}{c}\text { Non-Disease } \\
\text { Related }\end{array}$ & $0.04^{\mathrm{a})}$ \\
\hline \multirow{4}{*}{ Low } & \multirow{4}{*}{0.10} & \multirow{2}{*}{$\begin{array}{l}\text { Operation Iraqi } \\
\text { Freedom } \\
\text { 2003-2007 (US) }\end{array}$} & All Causes & $0.42^{[11]}$ \\
\hline & & & Combat Only & $0.34^{[11]}$ \\
\hline & & \multirow{3}{*}{$\begin{array}{l}\text { Kandahar, } \\
\text { Afghanistan } \\
\text { 2006-2011 } \\
\text { (Canada) }\end{array}$} & $\begin{array}{c}\text { Personnel in } \\
\text { Kandahar }\end{array}$ & $0.96^{[12,13]}$ \\
\hline & & & $\begin{array}{c}\text { Personnel Inside } \\
\text { Airfield }{ }^{\text {b) }}\end{array}$ & $0.06^{[12,13]}$ \\
\hline \multirow{3}{*}{ Moderate } & \multirow{3}{*}{1.0} & & $\begin{array}{l}\text { Personnel } \\
\text { Outside Air- } \\
\text { field }^{\text {b) }}\end{array}$ & $1.9^{[12,13]}$ \\
\hline & & \multirow{2}{*}{$\begin{array}{c}\text { Vietnam War } \\
\text { 1965-1974 (US) }\end{array}$} & All Causes & $2.2^{[11]}$ \\
\hline & & & Combat Only & $1.8^{[11]}$ \\
\hline \multirow{3}{*}{ High } & \multirow{3}{*}{10} & \multirow[b]{2}{*}{$\begin{array}{l}\text { Battle of the } \\
\text { Bulge (US) }\end{array}$} & $\begin{array}{c}\text { All Causes } \\
16 \text { Dec } 1944 \\
\text { to } 25 \text { Jan } 1945\end{array}$ & $25^{c)}$ \\
\hline & & & $\begin{array}{c}\text { All Causes } \\
19 \text { Dec } 1944 \\
-6 \text { Jan } 1945 \\
\text { (101 } 191^{\text {st }} \text { Airborne } \\
\text { only) }\end{array}$ & $45^{\text {d) }}$ \\
\hline & & $\begin{array}{l}\text { Battle of Britain } \\
\text { WWII (Allied) }\end{array}$ & $\begin{array}{l}\text { Combat Only } \\
\text { (active pilots } \\
\text { only) }\end{array}$ & $49^{e)}$ \\
\hline Extreme & $\begin{array}{l}70 \text { to approaching } \\
100\end{array}$ & $\begin{array}{c}\text { Kamikaze } \\
\text { Missions WWII } \\
\text { (Japan) }\end{array}$ & \multicolumn{2}{|l|}{-} \\
\hline
\end{tabular}

a) Tab. 2 - Annual deaths per 100000 persons aged 20-24 years [10]

b) Assumed half troops at airfield at all times. Average number of troops is 2595 with 141 fatalities outside the airfield, 5 fatalities inside the airfield

c) 610000 US troops, 19000 fatalities, duration of 40 days [14]

d) 11800 troops ( $101^{\text {st }}$ Airborne), 341 fatalities, duration of 18 days [15]

e) 2367 allied pilots, 446 fatalities, duration of 113 days [16] 
The concept of differing risk levels for bridges based on the type of military operation is not new. During World War II, Britain developed a military-specific classification for roughly 40000 bridges of importance throughout the country [17]. In establishing allowable stresses to calculate bridge strengths, Chetteo [17] states: "Clearly, when the country was in danger of invasion, the use of normal stresses would have laid too much restriction on military movements". Such classification would be used during“... actual fighting or manoeuvres - and it was felt that the stresses chosen should be as high as possible - subject to the proviso that a reasonable number of the heaviest loads allowable would not damage the bridges”. A higher allowable stress of $50 \%$ in excess of normal was used to assess and classify bridges. In some cases, dual classifications were given with the lower classification based on allowable stresses of $25 \%$ in excess of normal [17]. In the case of "dual classifications, the military authorities were asked to use the lower or "routine" figure whenever possible” [17]. For more extreme situations“... it was made clear to the military authorities that the assessment made did not represent the ultimate strength of the bridges, and that, if necessary in the course of actual fighting, loads perhaps twice as great could have been taken across without actual collapse, though the bridges might be irreparably damaged in so doing" [17]. Given that a land invasion of Britain in World War II might have allowed for a HIGH or EXTREME ARL for Allied Forces in the conduct of warfighting, it is reasonable that greater risks of bridge failure were deemed acceptable following Chetteo's recommendations.

\subsection{NATO Standardized Agreement 2021 - “Risk Crossing”}

NATO Standardized Agreement 2021 [18] specifies that if a vehicle with a specified Military Load Classification (MLC) that"... is less than or equal to the MLC of the bridge..., the vehicle can cross the bridge...; otherwise it must be diverted”. However, “... under exceptional operational conditions, this prohibition may be lifted on special decision of the theatre commander in the operational zone, or on that of civil authorities in areas under their control". These exceptions would be considered "risk crossings". Given that each mission within a military operation has an ARL that would correspond to a unique level of risk during bridge crossings, a crossing need not be considered a "risk crossing" that required theatre commander approval unless the risk level corresponding to the ARL of the mission was exceeded. There could be further restrictions for bridges along designated Main Supply Routes (MSRs), where a bridge failure may result in strategic consequences. This would give lower levels of command the flexibility necessary to gain the initiative in higher risk missions. If mission risk analysis indicated that crossing a certain bridge was required for mission success, and this activity was a lower risk than the ARL of the operation, it would not require higher command approval since this risk is implicitly allowed given the ARL set by higher command.

\subsection{Acceptable Risk Level (ARL) and Maximum Allowable Probability of Bridge Fatality}

To quantify the appropriate bridge crossing risk by the military in the absence of civilians, an acceptable risk baseline is necessary. The life-safety risk due to bridge failure during a crossing should be lower than that for the associated military activities, which is the ARL or the expected losses of the military operation. 
Acceptable risk for civilian bridge design and evaluation has been defined and is the basis of the calibration of civilian Limit State Design standards. The annual risk of fatality associated with bridges in Canada is in the order of $0.1 \times 10^{-6}$, which "has been associated with a satisfactory fatality rate for bridge users" [19]. Railway lines have deemed that $1 \times 10^{-6}$ is an acceptable annual probability of fatality [20]. In comparing the fatality rates of different activities, Menzies [21] found that for short and medium span bridges the maximum annual "socially acceptable risk of accidental death to members of the public associated with normal highway bridge collapse [is $1 \times 10^{-6}$ per year]". Menzies [21] approached the problem using the fatal accident rate of driving by car of $150 \times 10^{-6}$ as an upper bound and the background fatal accident rate at home of $10 \times 10^{-6}$ as a lower bound. The "statistics for all types of accident suggest that a fatal accident rate of about $\left[20 \times 10^{-6}\right]$ would be an acceptable value relating to bridge collapse" [21]. He lowered this value upon consideration of subjective attitudes associated with voluntary and involuntary exposure to risk, concluding "on the basis that the risk of loss of life caused by bridge collapse is an involuntary one, the acceptable probability for such an event is in the region of $0.1 \times 10^{-6}$ to $1 \times 10^{-6}$ ” [21].

Adopting Menzies' perspective, it could be argued that military activities in Canada, including bridge crossings, are voluntary. Thus under a NEGLIGIBLE ARL it would be deemed acceptable for military personnel to assume an annual life-safety risk during a bridge crossing of $20 \times 10^{-6}$. However, given that the Canadian Department of National Defence (DND) under its Ammunition Safety Program suggests that "the organization must strive to meet high standards in terms of accident prevention" [22] with annual probability of fatality due to an accident related to ammunition of about $20 \times 10^{-6}$ (22 deaths between 1983-2005, with the assumption of roughly 50000 personnel) it would seem necessary, under normal peacetime circumstances, to lower the annual probability of fatality to $1 \times 10^{-6}$ as proposed by Menzies [21].

Tab. 2 shows the annual death rates of Canadians due to various causes as reported by Statistics Canada [10]. The average annual probability of fatality for all causes, excluding disease, for Canadians aged between 20 and 24 years is $407 \times 10^{-6}$. The societal acceptable annual life-safety risk for bridge crossings is $1 \times 10^{-6}$ or $1 / 400^{\text {th }}$ of the average annual probability of fatality for all causes, excluding disease, for Canadians aged between 20 and 24 years of age. Thus the life-safety risk for bridge crossings by military personnel could reasonably be taken as 1 / 400 of the associated ARL.

Fig. 1 shows this relationship between probability of bridge fatality and ARL. The annual risk of fatality is maintained at $1 / 400^{\text {th }}$ the ARL, and so increases linearly with ARL for ARL greater than $0.04 \%$. Thus

$$
P_{f 0}=S P_{f \mathrm{ARL}}
$$

where:

- $P_{f o}$ is the acceptable annual probability of military personnel fatality due to bridge failure;

- $P_{\text {fARL }}$ is annual probability of fatality corresponding to the ARL;

- $S$ is the constant of proportionality, taken as $1 / 400=0.0025$.

For $P_{f \mathrm{ARL}}<0.04 \%$, the annual fatality risk limit of $1 \times 10^{-6}$ proposed by Menzies [21] governs. This relationship seems appropriate when the ARL is LOW or MODERATE, where the risk associated with bridge crossings is negligible compared to all other risks assumed by military personnel. At these ARLs it is expected that military units at the end of the operation or mission will remain fit for further combat [9]. 
Tab. 2 Annual deaths per 100000 persons aged 20-24 years [10]

\begin{tabular}{|c|c|c|c|c|c|c|}
\hline \multirow{2}{*}{\begin{tabular}{c} 
Cause of Death \\
\cline { 2 - 6 }
\end{tabular}} & $\mathbf{2 0 0 5}$ & $\mathbf{2 0 0 6}$ & $\mathbf{2 0 0 7}$ & $\mathbf{2 0 0 8}$ & $\mathbf{2 0 0 9}$ & \multirow{2}{*}{ Average } \\
\hline Disease & 16.6 & 17.8 & 14.2 & 15.1 & 14.9 & 15.7 \\
\hline $\begin{array}{c}\text { Intentional Self-Harm } \\
\text { (Suicide) }\end{array}$ & 13.2 & 11.7 & 12.8 & 11.2 & 11.9 & 12.2 \\
\hline Assault (Homicide) & 3.8 & 3.4 & 4.0 & 4.5 & 3.9 & 3.9 \\
\hline Legal Intervention & 0.1 & 0.1 & 0.0 & 0.1 & 0.0 & 0.1 \\
\hline $\begin{array}{c}\text { Events of undetermined } \\
\text { intent }\end{array}$ & 1.3 & 1.9 & 1.9 & 2.0 & 1.4 & 1.7 \\
\hline Motor Vehicle Accidents & 17.5 & 15.7 & 17.4 & 14.7 & 12.5 & 15.6 \\
\hline Other Transport Accidents & 1.0 & 1.1 & 0.8 & 1.0 & 0.6 & 0.9 \\
\hline $\begin{array}{c}\text { Accidental Drowning and } \\
\text { Submersion }\end{array}$ & 0.8 & 1.1 & 0.9 & 0.9 & 0.9 & 0.9 \\
\hline $\begin{array}{c}\text { Other Non-transport } \\
\text { Accidents }\end{array}$ & 5.5 & 5.4 & 5.0 & 5.8 & 5.9 & 5.5 \\
\hline \hline $\begin{array}{c}\text { Sum - Accidental Cause of } \\
\text { Death }\end{array}$ & 24.8 & 23.3 & 24.1 & 22.4 & 19.9 & 22.9 \\
\hline $\begin{array}{c}\text { Sum - Non-Disease Relat- } \\
\text { ed Death }\end{array}$ & 43.2 & 40.4 & 42.8 & 40.2 & 37.1 & 40.7 \\
\hline Sum - All Causes of Death & 59.8 & 58.2 & 57.0 & 55.3 & 52.0 & 56.5 \\
\hline
\end{tabular}

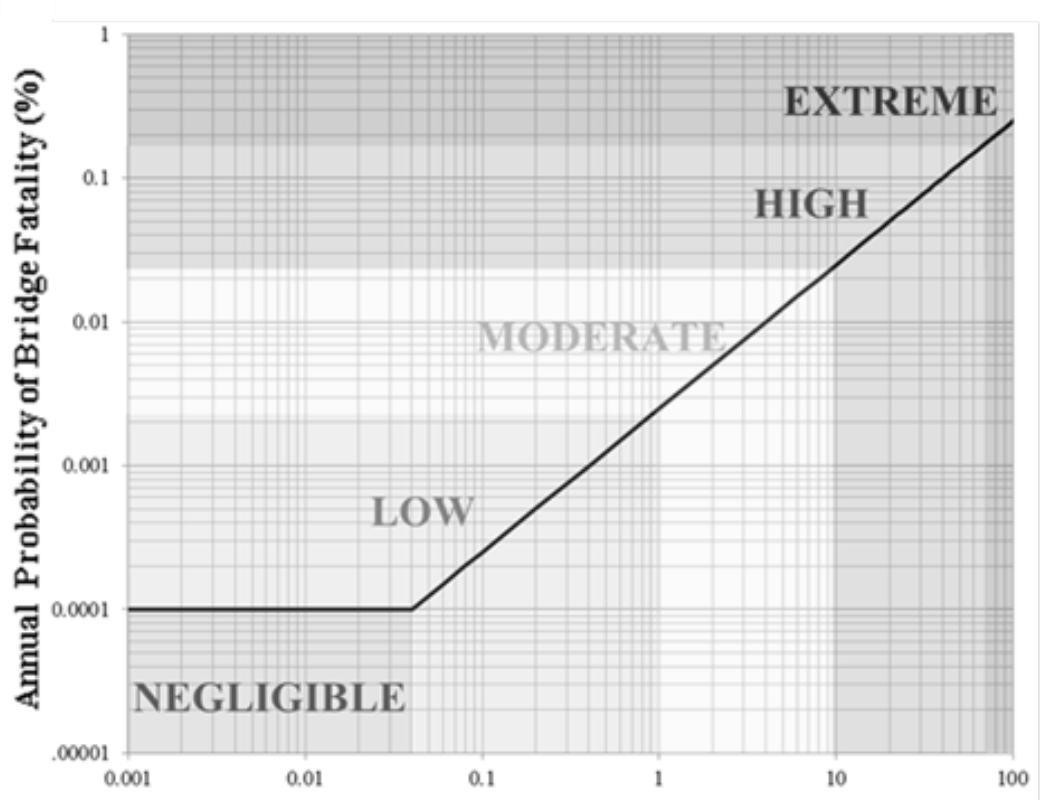

Acceptable Risk Level (ARL) Annual Probability of Fatality (\%)

Fig. 1 Acceptable annual risk continuum for military bridge crossings 
In general, over the long-term, a conflict can be expected to experience fatalities at an ARL of LOW or MODERATE, since the conflict would not continue at a sustained ARL of HIGH or EXTREME. Over the course of a conflict, individual military units in the conduct of the operation may be exposed to an ARL of HIGH or EXTREME for short periods of time (days to months) on individual missions, and would likely sustain losses that would render the units unfit for further combat. At these higher ARLs, the $P_{f o}$ computed using Eq. (2) could be too conservative. This is best illustrated by looking at the EXTREME ARL, where "losses may result in complete force annihilation" [9]. In its most simplistic sense, in military operations, bridges are obstacles between the current and desired locations of military assets required to complete the mission. Thus for a mission given the highest possible ARL (i.e. $P_{f A R L} \rightarrow 100 \%$ ), risks taken to get military assets where they are required, such as crossing bridges, should have an upper limit corresponding to the unit remaining combat effective after completing the crossing. As defined by US military doctrine, a military unit is considered to be combat capable at $85 \%$ or greater strength [23]. This value of $85 \%$ is being put forth for simplicity as a general approach lacking mission specific information. It is evident that at less than $100 \%$ strength and greater than $85 \%$ strength a unit will be less combat capable than at $100 \%$ and that under $85 \%$ strength a unit is not rendered incapable of successfully completing missions, although it may be severely hindered.

For example, assume that a single bridge needs to be crossed to engage the enemy. If the bridge fails by rendering the crossing unfit for use, any military vehicles that had not yet crossed can no longer support the mission. Although several bridges might need to be traversed, only one may contribute significantly to the risk. Thus, the goal of maintaining combat capability as defined by [23] would require that $85 \%$ of the mission critical vehicles will successfully cross the bridge with for example, $99.75 \%$ probability, before it is rendered non-functional. The size and vehicle composition of the mechanized military unit, specifically the number of limiting vehicle types involved in the mission, must therefore be considered. For example, an armoured brigade typically includes main battle tanks, infantry fighting vehicles and support vehicles; the main battle tank causes the most severe load effects and so would be the limiting vehicle considered for evaluation. The location of the limiting vehicles in the overall convoy (i.e., order of road movement) would also need to be considered in the planning stage because these vehicles are most likely to render the crossing unfit for use by the vehicles that follow.

Given that vehicle loading events on bridges are generally assumed independent and identically distributed [24-26], in assuming that multiple limiting vehicles are not present on the bridge at the same time, to determine the acceptable event probability of failure, the binomial probability distribution was used

$$
P_{Y}(y)=\left(\frac{n_{\min } !}{y ! n_{\min } !}\right) p_{y}(1-p)^{n_{\min }-y},
$$

where:

- $\quad p$ is the probability that a single vehicle crossing causes the bridge to fail (e.g. where the combined probabilistic load effects exceed the probabilistic capacity of the structure to resist the load effects rendering the crossing unfit for use by subsequent vehicles); 
- $n_{\min }$ is the minimum number of limiting vehicles required to cross (which would normally be taken as a percentage of total number of limiting vehicles, $n$ );

- $y$ is the number of failures;

- $P_{Y}(y)$ is the probability that exactly $y$ failures occur in $n_{\min }$ trials.

When $y=0$, Equation (3) simplifies to

$$
P_{Y}(0)=(1-p)^{n_{\min }},
$$

where:

- $P_{Y}(0)$ is the probability that $n_{\min }$ vehicles can successfully cross prior to failure. Equation (3a) can be rearranged to solve for $p$ given $n_{\min }$ and $P_{Y}(0)$

$$
p=1-\left[P_{Y}(0)\right]^{n_{\min }^{-1}} .
$$

Given that HIGH and EXTREME ARLs would be more likely employed for mission or situation-specific circumstances (such as individuals operating limiting vehicles within a convoy) and so are not likely to be present for long periods of time, it is beneficial to quantify event risk for each vehicle crossing. In order to relate probability of bridge failure to risk, as previously defined, it must be assumed that:

- only the limiting vehicles (counted in the $n_{\min }$ trials) are considered in the risk of fatality;

- each of the limiting vehicles carry the same number of personnel;

- should a failure occur it will result in fatalities for all personnel in the vehicle;

- only a single vehicle is present on the bridge at a time.

Tab. 3 presents the event risk for the crossing of $n$ limiting vehicles, where greater than $n_{\min }$ (taken as $0.85 n$, rounded up to the nearest integer) vehicles must meet a minimum probability, $P_{Y}(0)$, that they will successfully cross the bridge prior to a failure by overloading that renders the bridge non-functional for subsequent vehicles. $P_{Y}(0)$ at each ARL is taken such that when $n=1$, the event probability of failure does not exceed the annual risk given in Eq. (2). Tab. 3 does not relate specifically to annual risk because it defines only the risk associated with a single bridge crossing by $n$ vehicles for a particular mission. In other words, the event risk values shown in Tab. 3 , are the maximum risks permissible, without situation specific considerations of impact of overall mission success or failure, to ensure a mission involving $n$ limiting vehicles has a sufficient probability of remaining combat capable after a bridge crossing. It is unknown how often HIGH or EXTREME ARL crossings would occur per year (if at all) due to the highly unpredictable nature of warfare. For comparison the ARL daily risk of fatality, $P_{f d}$, is given in Tab. 3. Using a variant of Eq. (1) this is calculated by dividing each year into a series of 365 days

$$
P_{f \mathrm{~d}}=1-\left(1-P_{f y r}\right) \frac{1 \text { day }}{365 \text { days }} \text {. }
$$

Fig. 1 and Tab. 3 can be used as guidance for determining the minimum level of reliability when evaluating bridges based on the ARL specified by a commander or conversely after an engineer has quantified the reliability of a bridge, a means to report the corresponding level of risk through the chain of command.

An example of their application would occur at the beginning of a hypothetical combat mission. Early in the mission, the ARL for the theatre of operations is designated by the commander as MODERATE (1\% to $10 \%$ probability of fatality). This was decided on the basis of the type of enemy forces, and need to gain military ad- 
Tab. 3 Event risk for single bridge crossing by a convoy of $n$ vehicles

\begin{tabular}{|c|c|c|c|c|c|c|c|}
\hline \multirow{2}{*}{$\begin{array}{c}\text { ARL } \\
\text { Boundary }\end{array}$} & \multirow{2}{*}{\begin{tabular}{|c|} 
ARL \\
annual \\
risk of \\
fatality \\
$(\%)$
\end{tabular}} & \multirow{2}{*}{\begin{tabular}{|c|} 
ARL \\
daily \\
risk of \\
fatality \\
$(\%)$
\end{tabular}} & \multirow{2}{*}{\begin{tabular}{|c|}
$P_{y}(0)$ \\
Probability \\
that $85 \%$ \\
Vehicle \\
Cross $(\%)$
\end{tabular}} & \multicolumn{4}{|c|}{$\begin{array}{c}\text { Event Risk of Bridge Failure (\%) for } \\
\text { Number of } \\
\text { Vehicles Crossing (n) }\end{array}$} \\
\hline & & & & 1 & 10 & 100 & 1000 \\
\hline EXTREME & 99.99 & 2.5 & 99.75 & 0.25 & 0.028 & $2.9 \times 0^{-3}$ & 2.9 \\
\hline $\begin{array}{l}\text { HIGH/ EX- } \\
\text { TREME }\end{array}$ & 70 & 0.3 & 99.825 & 0.175 & 0.019 & $2.1 \times 10^{-3}$ & $2.1 \times 10^{-4}$ \\
\hline $\begin{array}{c}\text { MODERATE/ } \\
\text { HIGH }\end{array}$ & 10 & 0.03 & 99.975 & 0.025 & $2.8 \times 10^{-3}$ & $2.9 \times 10^{-4}$ & $2.9 \times 10^{-5}$ \\
\hline $\begin{array}{c}\text { LOW/ MOD- } \\
\text { ERATE }\end{array}$ & 1 & 0.003 & 99.9975 & $2.5 \times 10^{-3}$ & $2.8 \times 10^{-4}$ & $2.9 \times 10^{-5}$ & $2.9 \times 10^{-6}$ \\
\hline $\begin{array}{c}\text { NEGLIGIBLE/ } \\
\text { LOW }\end{array}$ & 0.04 & 0.0001 & 99.9999 & $1 \times 10^{-4}$ & $1.1 \times 10^{-5}$ & $1.2 \times 10^{-6}$ & $1.2 \times 10^{-7}$ \\
\hline
\end{tabular}

vantage to capture a high-value target. Thus, military engineers rate the Load Classification (MLC) of existing bridges in the theatre of operations for a MODERATE ARL using Fig. 1 (annual probability of bridge fatality ranging from $0.0025 \%$ to $0.025 \%$ ). During the combat mission, the location of a particular high-value target is identified. Military planners estimate that ten MLC 22 (Wheeled) vehicles would likely be sufficient to capture the high-value target. However, they would need to cross an MLC 14 (Wheeled) bridge, rated for a MODERATE ARL. The proximity of the bridge to the high-value target requires that the crossing be uncontrolled. Military engineers are requested to determine the reliability of the crossing, which they deem to correspond to an event life-safety crossing risk of $0.006 \%$. From Tab. 3, this is equivalent to a HIGH ARL crossing and so implies more risk than the MODERATE ARL designation for the mission. With this information, the commander can decide to accept this level of risk in using the bridge, or consider alternative options.

\section{Conclusions}

In military operations, varying levels of risk can be appropriate to achieve mission success. By conducting a risk assessment, a military commander may benefit by allowing personnel to assume greater risks in bridge crossings. The acceptable lifesafety risk of crossing bridges is defined as being proportional to the overall life-safety risk (e.g. Acceptable Risk Level) of individual military personnel. Should this Acceptable Risk Level change, by maintaining this proportionality, the acceptable lifesafety risk in using bridges will also change. Fig. 1 and Tab. 3 outline the maximum acceptable risk of bridge failure given the ARL of the associated military mission. This maximum acceptable risk is an upper bound of the optimal risk for bridges crossings by military vehicles. This continuum of acceptable life-safety risk for bridge crossings by military personnel provides military commanders with flexibility in mission planning and execution, while providing engineers a basis to conduct military bridge evaluation that is consistent with the mission intent. 


\section{Acknowledgement}

The authors would like to thank the Canadian Department of National Defence and National Sciences and Engineering Research Council (NSERC) for financial support, as well as access to technical information pertaining to this research.

Finally, the authors would like to extend a special acknowledgement of thanks to Dr. Rusmir Tanovic (deceased 2015), of the Royal Military College of Canada. He worked closely with the authors in providing relevant insight and advice in the writing of this paper to ensure research was compatible with current military bridge evaluation.

\section{References}

[1] CANADIAN STANDARDS ASSOCIATION (CSA) S408-2011:2011, Guidelines for the development of limit states design standards, CSA Special Publication. Rexdale, Canada.

[2] CONSTRUCTION INDUSTRY RESEARCH AND INFORMATION ASSOCIATION (CIRIA), Report 63, Rationalisation of safety and serviceability factors in structural codes [Report]. London: Construction Industry Research and Information Association, 1977.

[3] CANADIAN DEFENCE ACADEMY, CANADIAN FORCES LEADERSHIP INSTITUE. Leadership in the Canadian Forces, Leading People. Ottawa: Her Majesty the Queen in Right of Canada, 2007.

[4] MAUCH, S.P. and SCHNEIDER, TH. The direct endangering of the living space (A proposed set of quantitative concepts) [Die unmittelbare Gefährdung unseres Leensraumes (Versuch eines quantitative Begriffssystems). Schweizer Archiv, 37 (6): 175-185, 1971]. NRC Technical Translation TT-1636. Ottawa: National Research Council, 1973.

[5] SYKORA, M., HOLICKY, M., LENNER, R. and MAŇAS, P. Target Reliability Levels for Existing Bridges Considering Emergency and Crisis Situations. Advances in Military Technology, 2014, vol. 9, no. 1, p. 45-57.

[6] ARMED FORCES EPIDEMIOLOGICAL BOARD. Injuries in the Military A Hidden Epidemic [Report]. Washington: Armed Forces Epidemiological Board, 1996.

[7] CANADIAN DEPARTMENT OF NATIONAL DEFENCE. Risk Management for CF Operations, Change 1 (B-GJ-005-502/FP-000). Ottawa: Government of Canada, 2007.

[8] US DEPARTMENT OF THE ARMY. Risk Management (FM 100-14). Washington: United States Army, 1998.

[9] WIGHT, T. Operational Commander's Risk Assessment: How much Can You Really Afford to Lose? [Naval War College - Thesis]. Newport: Defense Technical Information Center, 1997.

[10] Canadian Socioeconomic Database [online 2012-05-30]. Statistics Canada. [cited: 2013-06-18]. Available from: <http://www5.statcan.gc.ca/cansim/>.

[11] GOLDBERG, M.S. Death and Injury Rates of U.S. Military Personnel in Iraq. Military Medicine, 2010, vol. 175, no. 4, p. 220-226. 
[12] icasualties.org. [online 2013-06-16]. icasualties.org. [cited: 2013-06-18]. Available from: <http://icasualties.org/OEF/Nationality.aspx?hndQry=Canada .

[13] Timeline: Canadian deaths in Afghanistan. [online 2011-03-28] Canada.com. [cited 2013-09-10]. Available from: <http://www.canada.com/news/Timeline+ Canadian+deaths+Afghanistan/1037437/story.html $>$.

[14] Battle of the Bulge [online]. wikipedia.org. [cited 2014-11-03]. Available from: $<$ http://en.wikipedia.org/wiki/Battle_of_the_Bulge>.

[15] Siege of Bastogne [online]. wikipedia.org. [cited 2014-11-03]. Available from: $<$ http://en.wikipedia.org/wiki/Seige_of_Bastogne>.

[16] VANCATA, P. Statistics of the Battle of Britain [online]. Battle of Britain. [cited 2014-11-03]. Available from: <http://cz-raf.hyperlink.cz/BoB/stat.html>.

[17] CHETTEO, C.S. The Military Classification of Bridges in Great Britain. In The Civil Engineer in War, A Symposium of Papers on War-Time Engineering Problems, Volume 1 Airfield, Roads, Railways, and Bridges. London: The Institution of Civil Engineer, 1948, p. 360-364.

[18] NATO Standardisation Agreement (STANAG) 2021. Military Load Classification of Bridges, Ferries, Rafts and Vehicles. Edition 6.

[19] ALLEN, D.E. Canadian Highway Bridge Evaluation: Reliability Index. Canadian Journal of Civil Engineering, 1992, vol. 19, no. 6, p. 987-991.

[20] CREMONA, C. Structural Performance, Probability-based Assessment. Hoboken: Wiley, 2011.

[21] MENZIES, J.B. Bridge failures, hazards and societal risks. [book auth.] Parag C. Das. Safety of Bridges. London: Thomas Telford, 1997, p. 36-41.

[22] CHIEF REVIEW SERVICES. Evaluation of DND/CF Ammunition Safety Program - 1258-101-2 (CRS) [Report]. Canada: Department of National Defense, 2005.

[23] US DEPARTMENT OF THE ARMY and US DEPARTMENT OF THE NAVY. Operational Terms and Graphics (FM 1-02/MCRP 5-12A). Washington, 2004.

[24] NOWAK, A.S. Live load model for highway bridges. Structural Safety, 1993, vol. 13, p. 53-66.

[25] NOWAK, A.S. and Hong, Y.K. Bridge Live-Load Models. Journal of Structural Engineering, 1991, vol. 117, no. 9, p. 2757-2767.

[26] KENNEDY, D.J.L. et al. Canadian Highway Bridge Evaluation: Load and Resistance Factors. Canadian Journal of Civil Engineering, 1992, vol. 19, p. 9921006. 